\title{
Effects of Repeated Episodes of Generic Clinical Mastitis on Mortality and Culling in Dairy Cows
}

\author{
D. Bar, ${ }^{\star 1}$ Y. T. Gröhn, ${ }^{*}$ G. Bennett, † R. N. González,† J. A. Hertl, ${ }^{*}$ H. F. Schulte,† \\ L. W. Tauer, F F. L. Welcome,† and Y. H. Schukken† \\ *Section of Epidemiology and \\ †Quality Milk Production Services, Department of Population Medicine and Diagnostic Sciences, College of Veterinary Medicine, and \\ łDepartment of Applied Economics and Management, College of Agriculture and Life Sciences, Cornell University, Ithaca, NY 14853
}

\begin{abstract}
Bovine clinical mastitis $(\mathrm{CM})$ can be detrimental to a dairy farm's profitability, not only in terms of lost production and treatment costs, but also because of the loss of the cows themselves. Our objective was to estimate the effects of multiple occurrences of generic bovine CM on mortality and culling. We studied 16,145 lactations from 5 large, high-producing dairy herds, with 3,036 first, 758 second, and 288 third CM cases observed in the first 10 mo after calving. Generalized mixed models, with a random herd effect, were used to quantify the effect of CM on mortality and culling. Other control variables included in the models were parity, stage of lactation, and other diseases. Clinical mastitis in the current month significantly increased mortality in all parities. Among primipara, odds ratios and $95 \%$ confidence intervals were $5.6(1.7,18.0), 23.3$ (7.1, 76.2), and 27.8 (3.7, 209.9) for the first, second, and third CM episode, respectively. Among multipara, respective estimates were $9.9(7.4,13.2), 12.0(8.0,18.0)$, and $11.5(6.1,21.4)$. Clinical mastitis significantly increased the risk of a cow being culled for a period of at least 2 mo after any $\mathrm{CM}$ case. Our findings provide dairy producers with information on mortality and culling associated with $\mathrm{CM}$ cases without considering the causative agent, and can also be used for economic analysis of CM management options.
\end{abstract}

Key words: clinical mastitis, mortality, culling, generalized mixed model

\section{INTRODUCTION}

Mastitis is a very common disease in dairy herds throughout the world (Barkema et al., 1998; RajalaSchultz et al., 1999; Sviland and Waage, 2002). The occurrence of mastitis can be detrimental to a dairy

Received June 19, 2007.

Accepted January 21, 2008.

${ }^{1}$ Corresponding author: db324@cornell.edu farm's profitability, not only because of lost production and increased treatment costs, but also because of decreased survival of the cow (Seegers et al., 2003). Clinical mastitis (CM) can be caused by many different pathogens, differing in their effects (Gröhn et al., 2004, 2005). The current situation on most farms, and for most cases, however, is that because CM milk is not cultured before treatment, farmers have to make treatment, culling, and prevention decisions without knowledge of the specific CM-causing agent.

Studies have shown the increased risk of a cow contracting CM being culled from the herd (Gröhn et al., 1998; Neerhof et al., 2000). For any economic analysis, however, there is a need to separate mortality from a decision of a farmer to sell the cow (i.e., culling). This distinction is essential because the economic outcome is different for a cow that dies on the farm and for a cow that is sold and generates sales revenue. In addition, in economic models that involve replacement policy optimization, it is necessary to separate events that are forced on the dairy farmer with some probability from an active culling decision determined by model calculations.

Although CM is often a recurring event (e.g., Houben et al., 1993; Döpfer et al., 1999; Zadoks et al., 2001), the effect of only the first case of CM on culling was estimated previously (Gröhn et al., 2005), because too few observations were available to address repeated $\mathrm{CM}$ cases as well. It is plausible to expect that repeated cases of CM will have a different impact on mortality and culling decisions than that determined by modeling only the first CM cases.

Recent studies (Neerhof et al., 2000; De Vliegher et al., 2005; Gröhn et al., 2005) on the effect of CM on culling used the semiparametric Cox model so that only the increased culling hazards were modeled, without calculating actual risks. An alternative approach to the semiparametric Cox model is to represent the survival time as a set of discrete time observations and indicators of whether an event occurred in each time unit (until the cow either experienced the event or was cen- 
sored), thereby assuming a constant hazard during each unit of time. In each time unit, the covariates are allowed to change (Allison, 1995). As a result, the dichotomous approach is more useful for inclusion of time-dependent covariates and the proportional hazards assumption is relaxed (Hedeker et al., 2000). The estimates from these models can be expressed directly as probabilities. As in the case of discrete data, the mean and variance are related (and often estimated by using a single parameter). Correct statistical treatment of discrete correlated data is of importance, not only for variance estimation, but also for estimation of the mean (Schukken et al., 2003). Because these are essentially generalized linear models, commercial software is readily available to incorporate multilevel random effects into these models (SAS Institute, 2006). Our objective in this paper was to estimate the effects of multiple occurrences of CM (within lactations) on mortality and culling by using generalized linear mixed model analysis.

\section{MATERIALS AND METHODS}

\section{Herd Description}

The data were from 5 dairy farms, located in New York State. These farms milked an average of 1,200, $1,100,750,650$, and 600 Holstein milking cows, respectively (rolling herd size for milking), and were followed for approximately 24 mo. Because we analyzed partial lactations also, and considering the fact that there are approximately $35 \%$ more calvings than milking cows (because of replacement), the resultant number of lactations analyzed was approximately 16,000.

The rolling herd average was close to $11,000 \mathrm{~kg}$ per cow/yr on a 305-d basis (range 10,700 to 11,500); monthly mean SCC was 225,000 cells $/ \mathrm{mL}$ (monthly range, 180,000 to 355,000 ) and varied relatively little among the 5 farms. Cows were housed in covered barns with concrete floors and free stalls and were classified by lactation, production, and reproductive status into feeding groups. All groups of cows were fed a balanced TMR via feed alleys with headlocks that allowed restraint of cows for examination and treatments. Cows were milked 3 times per day. Each milking unit had milk meters capable of automatically recording milk production and (on 2 farms) milk conductivity. Farm personnel used DairyComp305 herd management software (Valley Agricultural Software, Tulare, CA) to record lactation, reproductive, and medical data for each cow. Reliable data (because they were used by the herd personnel to manage the dairy) were readily available on parity, diseases, drying off, calving, and exit from the herd. Cows that were found dead or that had been euthanized because their expected beef price was less than the transportation costs, or that might have drug residues because of a medical treatment, were noted by the herd personnel as "Dead" with a remark containing the (often assumed) cause. Culled cows were noted as "Sold" (to a beef handler) with a remark for the culling reason. Because the decision to cull a cow is often a mixture of reasons, and examination of the data often showed discrepancies between the noted culling reason and the cow traits (e.g., low production as the culling reason for an open cow $450 \mathrm{~d}$ after calving), we decided to disregard this information for our analysis and treat culling as a generic event.

\section{Case Definition}

All lactating cows in the 5 study herds were eligible for inclusion in the study. All milkers on the cooperating farms were familiar with detection of CM by examination of foremilk. Most cases of CM were identified by milkers (warm, swollen udder or changes in the milk consistency), whereas others were detected by the herdsperson examining cows whose milk electrical conductivity had increased and who had a concurrent drop in milk production. Sick cows were treated according to well-defined protocols that were similar, but not completely the same (e.g., the exact supportive treatment given to cows), on all 5 farms and throughout the study (e.g., one farm also treated gram-negative CM cases with antibiotics in the first months of the study). Farm personnel sampled milk for microbiological culture from quarters with signs of CM. The samples were usually collected daily and were cultured by the Quality Milk Production Services laboratories. The bacteriological culture procedures are described in detail in Gröhn et al. (2004).

Some cows had 2 clinical episodes in the same quarter within several days of each other. Any such episode that occurred within $5 \mathrm{~d}$ (with either the same or a different etiologic agent isolated), or that occurred within $14 \mathrm{~d}$ with the same etiologic agent isolated from both occurrences, was considered the same case of mastitis. Any episode that occurred more than $14 \mathrm{~d}$ after the previous episode was considered a new CM case (Barkema et al., 1998).

\section{Other Diseases}

While focusing on CM, we also chose 5 other diseases for inclusion in the models as potential confounders. These 5 diseases are among the most common clinical conditions that are universally a problem in dairy cows. Reliable information about their occurrence was present in the data set for all farms. The rationale for including these diseases in the analysis is that they may be associated with mastitis and also affect herd life. 
The 5 recorded diseases (in addition to CM) were milk fever, retained placenta, metritis, ketosis, and displaced abomasum (DA). They were defined as follows (Gröhn et al., 2004): 1) milk fever occurred if a cow was unable to rise or had cool extremities and sluggish rumen motility near the time of calving, but was treated successfully with calcium; 2) retained placenta was retention of fetal membranes for at least $24 \mathrm{~h}$ postcalving; 3 ) metritis involved a febrile state accompanying a purulent or fetid vaginal discharge, or a diagnosis of an enlarged uterus by veterinary palpation; 4) ketosis was diagnosed by detection of ketones in milk or urine, and response to treatment; and 5) DA occurred when the abomasum was enlarged with fluid, gas, or both, and was mechanically trapped in either the left or right side of the abdominal cavity. Every effort was taken to ensure that disease definition and diagnostic criteria were consistent across herds. Written disease definitions were provided to the dairy producers and veterinarians involved.

\section{Statistical Methods}

The SAS procedure PROC GLIMMIX (SAS Institute Inc., Cary, NC; release June 2006) was used to study the effects of CM and several control variables (herd, parity, stage in lactation) on the odds of mortality of a cow, or the odds of being culled. Because we were not interested in an individual farm, but rather farms in general with these characteristics (i.e., large, highmilk-producing dairy farms with a low incidence of contagious mastitis), and we expected a correlation between cows in a given herd, herd was modeled as a random (intercept) effect. The other covariates were modeled as fixed effects.

Primipara and multipara were analyzed separately because of the differing risks of outcome and a potentially different CM effect. The first 2 mo of the lactation were analyzed separately from the latter part of the (standard 305-d) lactation, because otherwise a complex interaction term between the CM index (see below) and the stage in lactation was necessary. Because only a few cows had more than one CM in the first 2 mo of the lactation, only the first case of CM was considered in the analysis of this time period. The model for this time period also included calving diseases as confounders. For the latter part of the lactation, the first 3 cases of CM were analyzed. Higher order CM occurrences were not considered in the analysis because of the low numbers of observations on 4 or more CM occurrences. A $P$-value below 0.05 was considered significant for drawing inferences.

The generalized mixed model generalizes the standard model as follows:

$$
g(\mathbf{Y})=\mathbf{X} \beta+\mathbf{Z} \gamma+\varepsilon,
$$

where $g$ is a link function, $\mathbf{Y}$ is the vector of observations, $\beta$ is an unknown vector of fixed-effect parameters with known design matrix $\mathbf{X}, \gamma$ is an unknown vector of random-effect parameters with known design matrix $\mathbf{Z}$, and $\varepsilon$ is an unknown random error vector whose elements are no longer required to be independent and homogeneous. Vectors $\gamma$ and $\varepsilon$ are Gaussian random variables that are uncorrelated and have expectations $\mathbf{0}$ and variances $\mathbf{G}$ and $\mathbf{R}$, respectively. The variance of $g(\mathbf{y})$ is $\mathbf{V}=\mathbf{Z G} \mathbf{Z}^{\prime}+\mathbf{R}$ (when $\mathbf{R}=\sigma^{2} \mathrm{I}$ and $\mathbf{Z}=\mathbf{0}$, the generalized mixed model reduces to the standard generalized model).

The link function in our study was the natural log of the odds of a cow dying or being sold in a month (time step). Fixed effects in our models were (for multiparous cows) parity with 3 levels (second, third, and fourth and greater lactation number); stage in lactation with 2 levels (first and second month, and 3 to 5 and 6 to 10 mo for the 2 time periods analyzed); and CM index, which is detailed below. For the first time period after calving, we included in the $\mathbf{X}$ matrix 5 additional binary covariates (for milk fever, retained placenta, metritis, ketosis, and DA). The random effect was herd modeled as a random intercept (G matrix). For primiparous cows, the same model was used, except that the terms containing parity and milk fever were omitted, because they were not applicable. We chose the time step of 1 mo because of convergence problems when using weekly or daily time periods and because the economic model we intend to use has a monthly time step. Only the first $10 \mathrm{mo}$ of the lactation were included in the analysis because we did not want pregnancy status to have a confounding effect on culling decisions.

The CM coding schemes were determined after preliminary analysis of the data set, and are illustrated in Table 1. For mortality analysis, the CM index had 4 levels (values of levels are in parentheses): first CM case occurring in the current month of the lactation (1), second CM case (in the current lactation) occurring in the current month of the lactation (2), third CM case occurring in the current month of the lactation (3), and free of CM in that month (10). For culling analysis, another CM index with 10 levels (values of levels are in parentheses) was used: first CM case occurring in the current month of the lactation (1), first CM case occurring in the previous month (2), first CM case occurring 2 or more months ago (3), second CM case occurring in the current month of lactation (4), second $\mathrm{CM}$ case occurring in the previous month $(5), \ldots$, third CM case occurring 2 or more months ago (9), and free of $\mathrm{CM}$ until that month (10). If $2 \mathrm{CM}$ codes were relevant for the same time period (e.g., $2 \mathrm{CM}$ cases in the same 
Table 1. Data for 4 example cows illustrating the covariate coding schemes used in the statistical analysis of this study

\begin{tabular}{|c|c|c|c|c|c|c|c|c|}
\hline $\begin{array}{l}\text { Cow } \\
\text { ID }\end{array}$ & $\begin{array}{l}\text { Month } \\
\text { in milk }\end{array}$ & $\begin{array}{l}\text { Month of } \\
\text { first } \\
\mathrm{CM}^{1} \text { case }\end{array}$ & $\begin{array}{l}\text { Month of } \\
\text { second } \\
\text { CM case }\end{array}$ & $\begin{array}{l}\text { Month of } \\
\text { third } \\
\text { CM case }\end{array}$ & $\begin{array}{l}\text { CM index } \\
\text { variable for } \\
\text { mortality }^{2}\end{array}$ & $\begin{array}{l}\text { CM index } \\
\text { variable for } \\
\text { culling }{ }^{3}\end{array}$ & Died & Sold \\
\hline 1006 & 1 & 3 & 7 & 10 & 10 & 10 & 0 & 0 \\
\hline 1006 & 2 & 3 & 7 & 10 & 10 & 10 & 0 & 0 \\
\hline 1006 & 3 & 3 & 7 & 10 & 1 & 1 & 0 & 0 \\
\hline 1006 & 4 & 3 & 7 & 10 & 10 & 2 & 0 & 0 \\
\hline 1006 & 5 & 3 & 7 & 10 & 10 & 3 & 0 & 0 \\
\hline 1006 & 6 & 3 & 7 & 10 & 10 & 3 & 0 & 0 \\
\hline 1006 & 7 & 3 & 7 & 10 & 2 & 4 & 0 & 0 \\
\hline 1006 & 8 & 3 & 7 & 10 & 10 & 5 & 0 & 0 \\
\hline 1006 & 9 & 3 & 7 & 10 & 10 & 6 & 0 & 0 \\
\hline 1006 & 10 & 3 & 7 & 10 & 3 & 7 & 0 & 0 \\
\hline 1012 & 1 & - & - & - & 10 & 10 & 0 & 0 \\
\hline 1012 & 2 & - & - & - & 10 & 10 & 0 & 0 \\
\hline 1012 & 3 & - & - & - & 10 & 10 & 0 & 0 \\
\hline 1012 & 4 & - & - & - & 10 & 10 & 1 & 0 \\
\hline 1025 & 1 & 2 & - & - & 10 & 10 & 0 & 0 \\
\hline 1025 & 2 & 2 & - & - & 1 & 1 & 0 & 1 \\
\hline $1030^{4}$ & 1 & 1 & 3 & 3 & 1 & 1 & 0 & 0 \\
\hline 1030 & 2 & 1 & 3 & 3 & 10 & 2 & 0 & 0 \\
\hline 1030 & 3 & 1 & 3 & 3 & 3 & 7 & 0 & 0 \\
\hline 1030 & 4 & 1 & 3 & 3 & 10 & 8 & 0 & 0 \\
\hline 1030 & 5 & 1 & 3 & 3 & 10 & 9 & 0 & 1 \\
\hline
\end{tabular}

${ }^{1} \mathrm{CM}=$ clinical mastitis.

${ }^{2}$ For mortality analysis, the CM index had 4 levels: 1 = first CM occurring in the current month of the lactation; 2 = second CM case (in the current lactation) occurring in the current month of the lactation; $3=$ third CM case occurring in the current month of the lactation; $10=$ free of CM in that month.

${ }^{3}$ For culling analysis, another CM index with 10 levels was used: 1 = first CM case occurring in the current month of the lactation; 2 = first $\mathrm{CM}$ case occurring in the previous month; $3=$ first $\mathrm{CM}$ case occurring 2 or more months ago; $4=$ second CM case occurring in the current month of lactation; $5=$ second CM case occurring in the previous month; .., 9 = third $\mathrm{CM}$ case occurring 2 or more months ago; $10=$ free of $\mathrm{CM}$ until that month.

${ }^{4}$ If $2 \mathrm{CM}$ codes were relevant for the same time period (e.g., $2 \mathrm{CM}$ cases in the same month), the code given was according to the last event. Cow 1030 demonstrates how such conflicts were treated.

month), the code given was according to the last event. Cow 1030 in Table 1 is an example of how such conflicts were treated.

\section{RESULTS}

\section{Descriptive Findings}

Our data set contained data on 16,145 lactations from the 5 herds. In the first 10 mo of the lactation, 3,036 cows had experienced their first $\mathrm{CM}$ case, 758 cows their second CM case, and 288 cows their third CM case. In the first 10 mo after calving, 960 cows died and 1,995 cows were sold (for any reason). The probability of a cow dying or being sold is graphically presented for primiparous cows in Figure 1 and multiparous cows in Figure 2.

Although we did not model the mastitis-causing pathogens separately in this study, the bacteriological results of the samples taken at the time of CM are presented in Table 2 . In the vast majority of the CM cases, no contagious pathogen was isolated; therefore, our initial definition of these 5 farms as having effective control programs against contagious mastitis was confirmed. The median day of lactation of the occurrence of the first CM episode was similar in both primipara (91) and multipara (90). In contrast, subsequent CM episodes occurred sooner in multipara than in primipara.

Because we were interested specifically in repeated occurrences of $\mathrm{CM}$, the number of real repeated cases caused by the same pathogen (detailed data not shown) is of interest. Among primipara, in $42 \%$ of the second $\mathrm{CM}$ cases, the same pathogen as in the first CM case was isolated; among multipara, the corresponding recurrence probability was $36 \%$. Among primipara, in $50 \%$ of the third CM cases, the same pathogen as in the first or second CM case was isolated; among multipara the corresponding proportion was $48 \%$. Therefore, slightly less than half of the repeated cases were caused by the same pathogen.

\section{Effects of the First CM Case on Mortality and Culling at the Beginning of the Lactation}

Parameter estimates from the models for the first 2 mo of the lactation are presented in Table 3. Clinical 


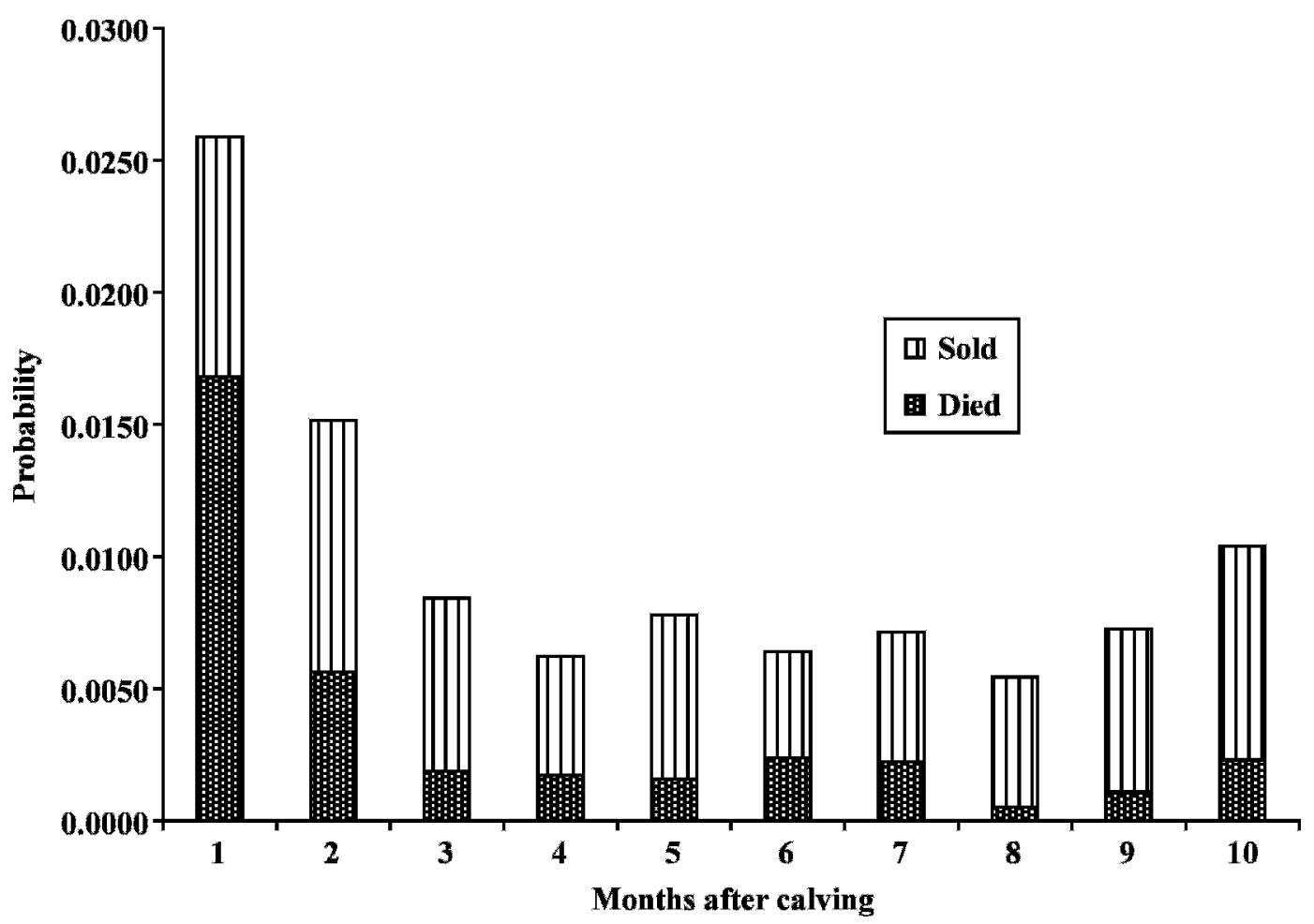

Figure 1. Probability of a cow dying (dotted pattern) or being culled (vertical lines) in 5,500 first lactations in 5 New York State dairy herds.

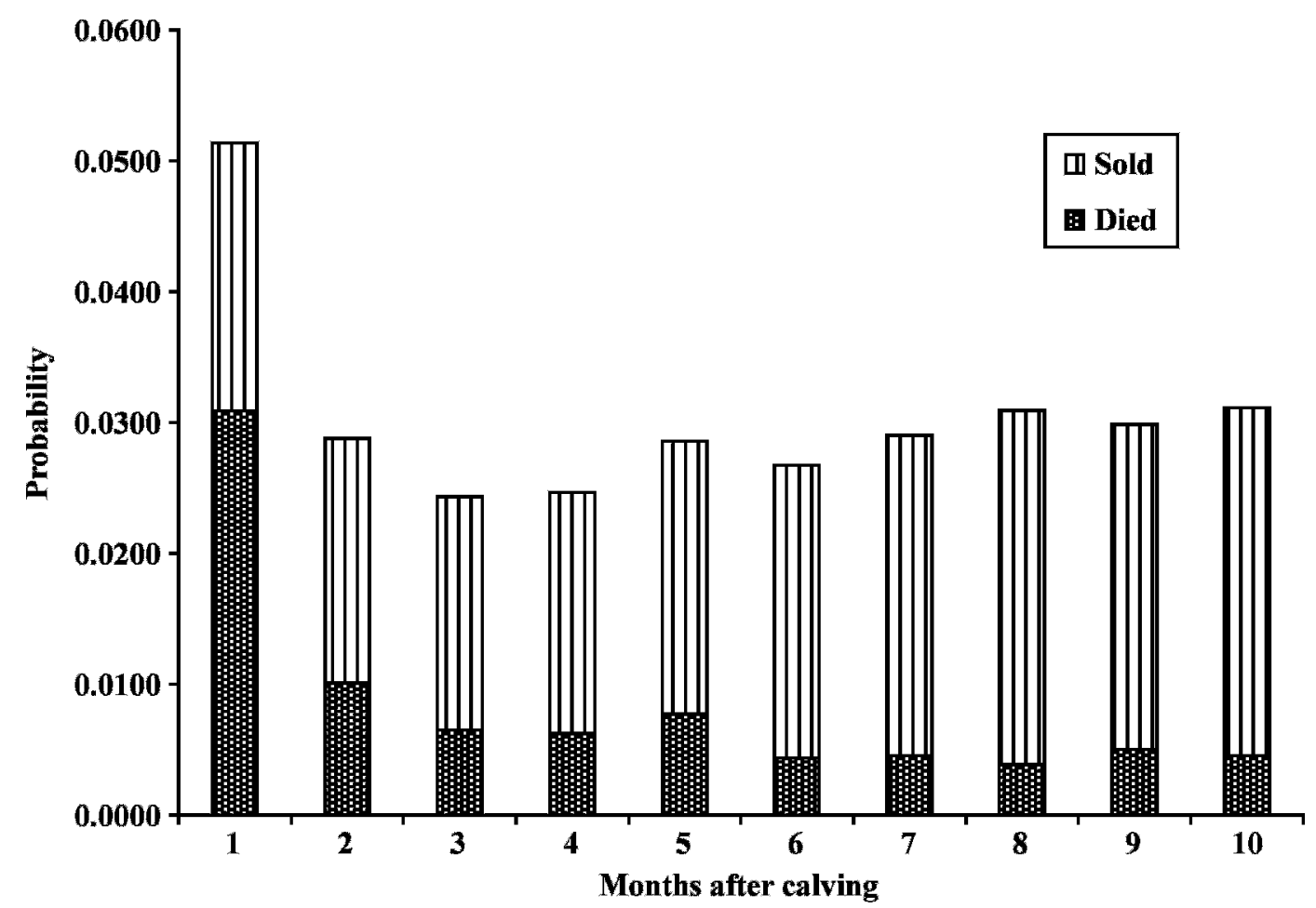

Figure 2. Probability of a cow dying (dotted pattern) or being culled (vertical lines) in 10,645 multiparous lactations in 5 New York State dairy herds. 
Table 2. Pathogens isolated from milk of the first, second, and third case of clinical mastitis (CM) in 16,145 lactations in 5 New York State dairy herds

\begin{tabular}{|c|c|c|c|c|c|c|}
\hline \multirow[b]{2}{*}{ Item } & \multicolumn{3}{|c|}{ Primipara $(\mathrm{n}=5,500)$} & \multicolumn{3}{|c|}{ Multipara $(\mathrm{n}=10,645)$} \\
\hline & $\begin{array}{l}\text { First } \\
\text { CM }\end{array}$ & $\begin{array}{l}\text { Second } \\
\text { CM }\end{array}$ & $\begin{array}{c}\text { Third } \\
\text { CM }\end{array}$ & $\begin{array}{c}\text { First } \\
\text { CM }\end{array}$ & $\begin{array}{l}\text { Second } \\
\text { CM }\end{array}$ & $\begin{array}{c}\text { Third } \\
\text { CM }\end{array}$ \\
\hline $\begin{array}{l}\text { Cases } \\
\text { Median day }\end{array}$ & $\begin{array}{r}644 \\
91\end{array}$ & $\begin{array}{l}100 \\
184\end{array}$ & $\begin{array}{r}26 \\
192\end{array}$ & $\begin{array}{r}2,393 \\
90\end{array}$ & $\begin{array}{l}658 \\
140\end{array}$ & $\begin{array}{l}262 \\
168\end{array}$ \\
\hline $\begin{array}{l}\text { Escherichia coli, \% } \\
\text { Klebsiella, \% } \\
\text { No growth, }{ }^{2} \% \\
\text { Streptococcus spp., \% } \\
\text { Staphylococcus aureus, \% } \\
\text { CNS, \% } \\
\text { Arcanobacterium pyogenes, \% } \\
\text { Yeast, \% } \\
\text { Other, }{ }^{3} \% \\
\text { Undefined, }{ }^{4} \%\end{array}$ & $\begin{array}{r}24 \\
6 \\
11 \\
23 \\
7 \\
6 \\
2 \\
3 \\
5 \\
13\end{array}$ & $\begin{array}{r}28 \\
10 \\
13 \\
20 \\
3 \\
1 \\
5 \\
4 \\
6 \\
10\end{array}$ & $\begin{array}{r}31 \\
12 \\
19 \\
0 \\
4 \\
12 \\
8 \\
0 \\
8 \\
8\end{array}$ & $\begin{array}{r}29 \\
10 \\
18 \\
18 \\
4 \\
4 \\
1 \\
3 \\
2 \\
9\end{array}$ & $\begin{array}{r}23 \\
12 \\
17 \\
19 \\
5 \\
2 \\
2 \\
1 \\
5 \\
10\end{array}$ & $\begin{array}{r}17 \\
19 \\
21 \\
18 \\
6 \\
2 \\
2 \\
1 \\
4 \\
10\end{array}$ \\
\hline
\end{tabular}

\footnotetext{
${ }^{1}$ Median day of lactation of CM occurrence.

${ }^{2}$ Fewer than 2 colonies per plate.

${ }^{3}$ Any organism not specified above.

${ }^{4}$ More than 3 different organisms isolated (i.e., contaminated sample).
}

mastitis in the current month increased $(P<0.001)$ mortality both in primipara [odds ratio $(\mathbf{O R})$ : $\exp (1.41)=4.1]$ and multipara $(\mathrm{OR}=2.3)$. Clinical mastitis increased $(P<0.001)$ the risk of a multiparous cow being culled for a period of 2 mo after diagnosis $(\mathrm{OR}=$ 3.4 and 2.9 for the same and the following month after $\mathrm{CM}$, respectively).

\section{Effects of the First 3 CM Cases on Mortality}

Parameter estimates from the models for mo 3 to 10 of the lactation are presented in Table 4. Clinical mastitis in the current month increased mortality $(P<$ 0.001). The odds of primiparous cows, in the month CM was diagnosed, dying were 5.6, 23.3, and 27.8 times greater for the first, second, and third CM episode, respectively, compared with a CM-free cow in that month. Among multipara, respective estimates were 9.9, 12.0, and 11.5 for the first, second, and third CM case, respectively.

\section{Effects of the First 3 CM Cases on Culling}

Parameter estimates from the models for mo 3 to 10 of the lactation are presented in Table 4. Clinical

Table 3. Effects of the first clinical mastitis (CM) case on mortality and culling in 16,145 lactations on 5 New York State dairy farms over the first 2 mo of the lactation ${ }^{1}$

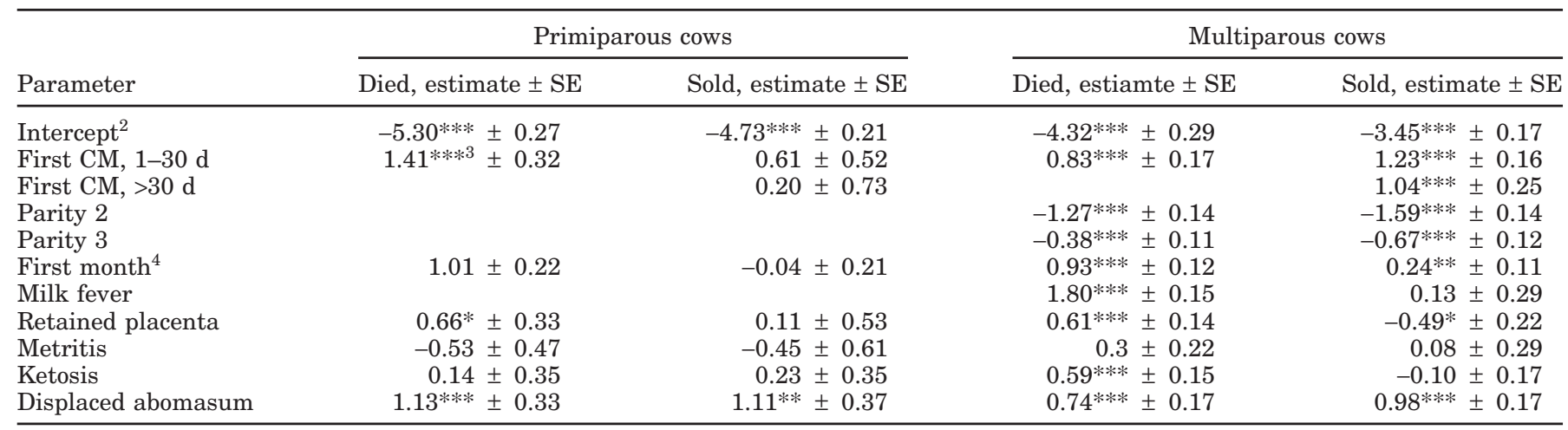

${ }^{1}$ Estimates were obtained from generalized mixed models with a random herd effect.

${ }^{2}$ In primiparous cows, the reference group is represented by a cow in the second month of the lactation, free of CM and calving diseases. In multiparous cows, the reference group is represented by a cow in the fourth and greater lactation, in the second month of the lactation, and free of $\mathrm{CM}$ and calving diseases.

${ }^{3}$ The odds ratio is calculated as $\exp (1.41)=4.1$.

${ }^{4}$ First month of lactation.

$* P<0.05 ; * * P<0.01 ; * * *<0.001$. 
Table 4. Effects of the first 3 clinical mastitis (CM) cases on mortality and culling in 14,323 lactations on 5 New York State dairy farms over mo 3 to 10 of the lactation ${ }^{1}$

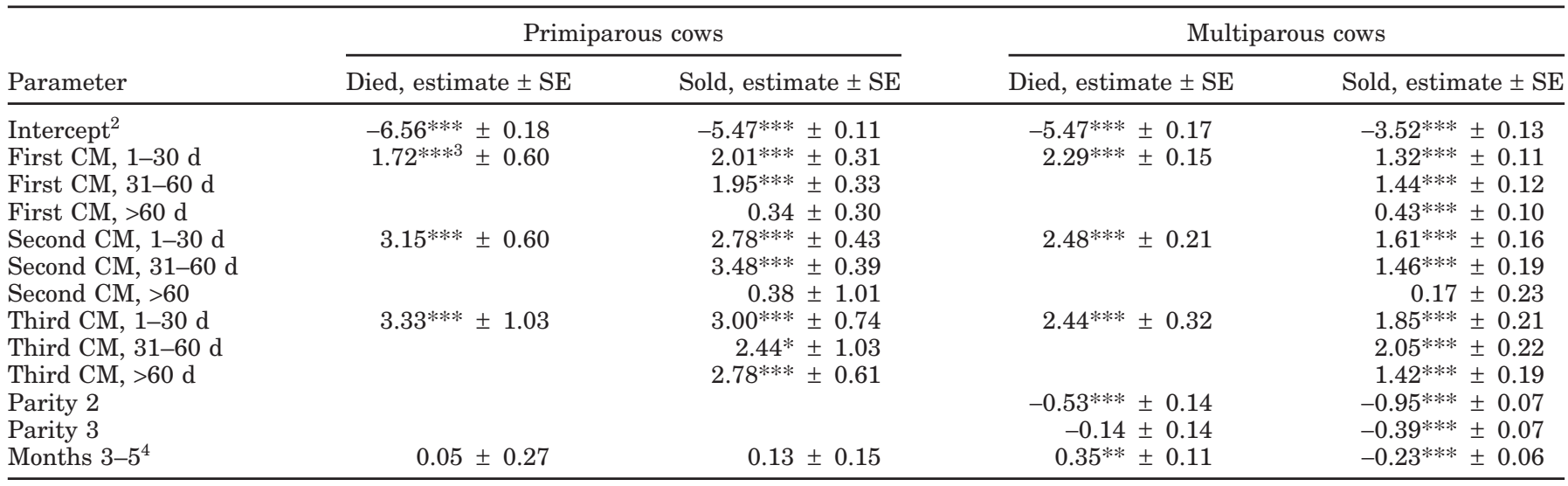

${ }^{1}$ Estimates were obtained from generalized mixed models.

${ }^{2}$ In primiparous cows, the reference group is represented by a cow in mo 6 to 10 of the lactation, and free of CM. In multiparous cows, the reference group is represented by a cow in the fourth and greater lactation, in mo 6 to 10 of the lactation and free of CM.

${ }^{3}$ The odds ratio is calculated as $\exp (1.72)=5.6$.

${ }^{4}$ Months 3 to 5 of lactation.

$* P<0.05 ; * * P<0.01 ; * * * P<0.001$.

mastitis increased $(P<0.001)$ the risk of a cow being culled in all parities for a period of at least 2 mo after diagnosis. After the third CM case, the odds of culling the cow were, even 2 mo after CM had occurred, more than 4 times as high as the odds of a cow without CM.

\section{Effects of the First 3 CM Cases on Productive Life}

Clinical mastitis increased both mortality and the risk of a cow being culled. The statistical models results presented in Tables 3 and 4 can be expressed easily in probability terms by exponentiation of the parameter estimates and transforming the resulting odds into probabilities. As an example, the probability of cows in their first lactation, 6 to 10 mo after calving, with the first CM case occurring in the current month, of dying is $\exp (-6.56+1.72) /[1+\exp (-6.56+1.72)]=0.0078$. In Figure 3 the effect of either the first, second, or third $\mathrm{CM}$ case occurring in the current month on the probability of cows in their first (A), second (B), third (C), or fourth and greater (D) lactation, 6 to 10 mo after calving, leaving the herd in this given month is graphically presented. Recurrent CM cases are of increasing detrimental effect on herd life.

\section{DISCUSSION}

Our objective was to analyze the decreased survival of cows after CM in 2 separate components: mortality (including euthanized cows) and culling (selling the cow for slaughter). Clinical mastitis increased the odds of a cow dying, regardless of the CM case number. Clinical mastitis also increased the odds of a cow being sold for slaughter. The increased risk of being sold was apparent for a period of at least 2 mo after CM and lasted for a long time if it was the third case in this lactation.

The overall mortality risk observed in our study is slightly greater than that estimated by Esslemont and Kossaibati (1997), but is in line with findings in all DHIA data recovered from the same area where these herds are located (Hadley et al., 2006). In that study, no CM records were available, but high SCC was still an important cause for early culling. The farmers in our study reported that approximately half of the dead cows were actually euthanized, similar to the estimate made by Thomsen et al. (2004). Long drug withdrawal periods, combined with high transportation costs to the slaughterhouse, often make this decision the most economical one. Nevertheless, such an outcome is still considered to be outside the decision process of a farmer and incurs only costs. On the other hand, the increased risk of cows being sold for slaughter after CM is due, at least in part, to an active comparison of the farmer's options to sell the cow and replace her with a new animal, or to treat the cow and keep her in the herd for at least another month.

Figure 2 shows relatively constant culling rates (for multiparous cows) throughout the standard 305-d lactation, after the first month. We also observed this phenomenon previously (Gröhn et al., 2005). This is because the second peak appears later, as a result of culling open cows (Gröhn et al., 1998). In the current study, we tried to avoid this effect and therefore analyzed only 

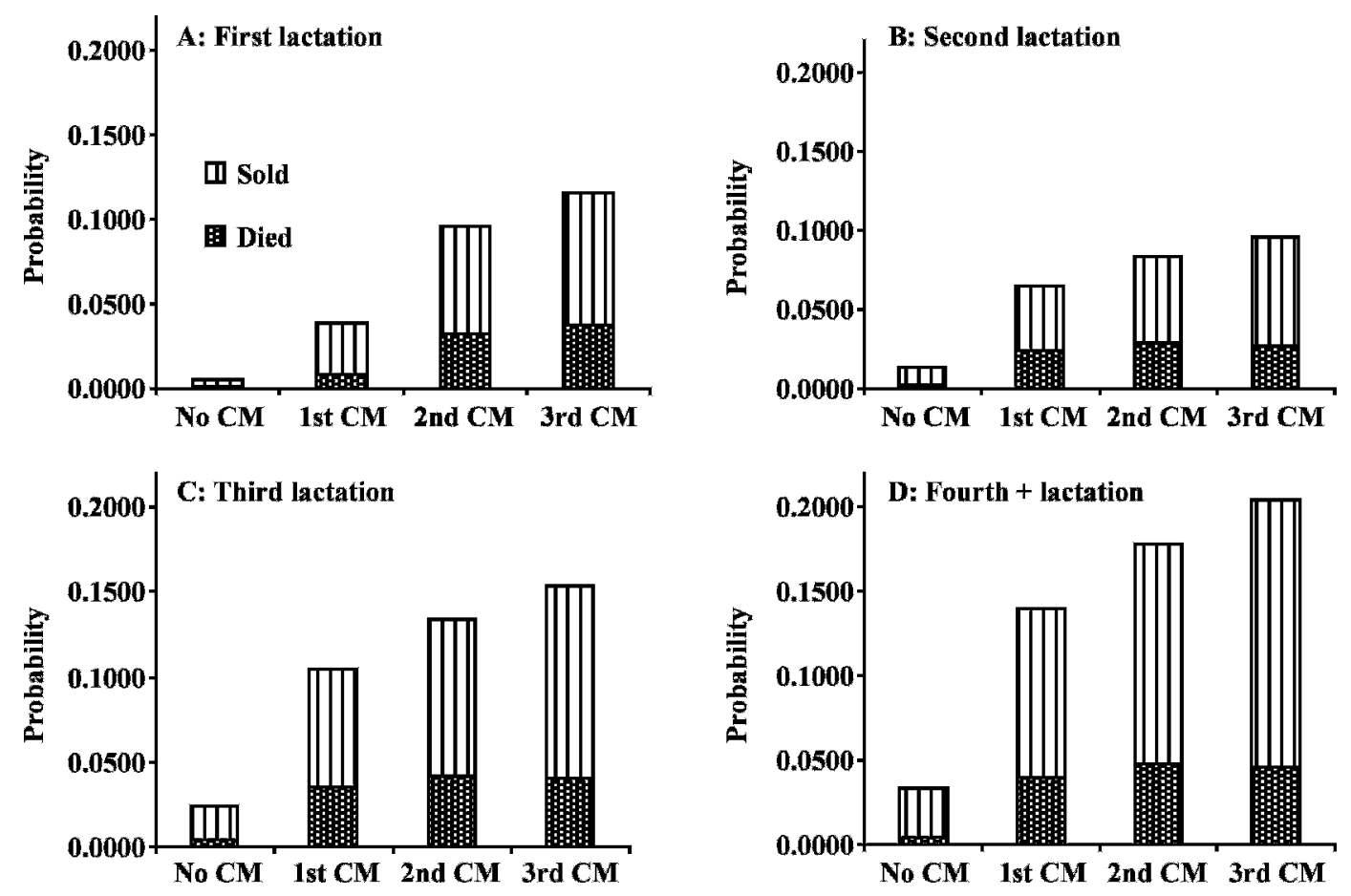

Figure 3. Probability of cows in their first (A), second (B), third (C), or fourth and greater (D) lactation, 6 to 10 mo after calving, dying (dotted pattern) or being culled (vertical lines) per month, if they were free of clinical mastitis (CM) or had their first, second, or third CM case in that month.

the first 10 mo of the lactation; in this period, culling of open cows has an effect, but only a minor one.

Although not often, $2 \mathrm{CM}$ cases were sometimes present in the same month, or a short time thereafter. The CM coding scheme we used in our analysis assigned all effects from previous CM cases to the last event in the same month. Because the cows were obviously not culled after the earlier events in the same month, this seems to be the more logical choice.

In all models, death related to $\mathrm{CM}$ remained the same or increased with increasing case number. It is difficult to think of a biological reason for increasing mortality in later (second, third) CM episodes. A possible explanation could be that owners became frustrated with a cow with repeated cases of $\mathrm{CM}$, and in some cases (e.g., if they expected very low net return from selling the cow), would euthanize her.

In a previous paper (Bar et al., 2007), we also observed in the same data that milk loss with each subsequent case of mastitis was approximately the same, particularly when accounting for production level at the time of occurrence. These findings would suggest that subsequent cases of mastitis present with a similar severity compared with the first case of a cow in a given lactation. Even though approximately half of subsequent cases are caused by the same organism, no apparent benefits (in terms of limited milk production loss or increased survival) are obtained from a previous case. This would agree with previous studies in which a very limited duration of presence of immunological memory or protection was observed after either vaccination (Burton and Erskine, 2003) or a full challenge (Lehtolainen et al., 2003). Vaccination studies often report a benefit of vaccination, but this benefit may be of relatively short duration, as suggested by Burton and Erskine (2003) or from our data, where a full inflammatory response offers little benefit for future infections with the same organism.

Although the OR of death and culling in CM cows was almost always greater in first-lactation animals vs. animals in second and greater lactation, given the same case number of mastitis, the resultant actual added mortality (approximately 1\% in primipara vs. $2 \%$ in multipara) and culling were lower because the basic odds in healthy primipara were much lower. This is in accordance with mastitis challenge studies, which show consistently that primipara respond less severely to the same challenge (Vangroenweghe et al., 2004).

Clinical mastitis can be caused by different pathogens, differing in their effects on milk yield (Gröhn et al., 2004) and on herd life (Gröhn et al., 2005). We treated CM as a generic entity because on most farms, and for most cases, CM milk is not cultured, and the farmers have to make treatment, culling, and preven- 
tion decisions without knowledge of the specific CMcausing agent. To better understand the biology of pathogen-specific mastitis, it would be essential to model pathogen-specific CM, especially when addressing repeated cases. The authors are well aware of this point, but a larger number of observations are needed to be able to address pathogen-specific repeated $\mathrm{CM}$; the current number of lactations in our study is not sufficient. We hope to fill this gap in the near future.

The estimates from this study can be directly incorporated into an appropriate economic model, because they can be expressed in actual monthly risks. The monthly time step of this analysis is in accordance with a replacement optimization and simulation model that we intend to construct and use to estimate the economic impact of CM.

\section{ACKNOWLEDGMENTS}

The USDA (Cooperative State Research, Education, and Extension Service, Washington, DC) Award No. 2005-35204-15714 provided funding for this study. The authors want to thank the owners and personnel of the 5 dairies, and the personnel of the Ithaca, Canton, and Geneseo Regional Laboratories, Quality Milk Production Services, for their valuable cooperation during the study.

\section{REFERENCES}

Allison, P. A. 1995. Survival Analysis Using the SAS System: A Practical Guide. SAS Institute Inc., Cary, NC.

Bar, D., Y. T. Gröhn, G. Bennett, R. N. González, J. A. Hertl, H. F. Schulte, L. W. Tauer, F. L. Welcome, and Y. H. Schukken. 2007. Effect of repeated episodes of generic clinical mastitis on milk yield in dairy cows. J. Dairy Sci. 90:4643-4653.

Barkema, H. W., Y. H. Schukken, T. J. Lam, M. L. Beiboer, H. Wilmink, G. Benedictus, and A. Brand. 1998. Incidence of clinical mastitis in dairy herds grouped in three categories by bulk milk somatic cell counts. J. Dairy Sci. 81:411-419.

Burton, J. L., and R. J. Erskine. 2003. Immunity and mastitis. Some new ideas for an old disease. Vet. Clin. North Am. Food Anim. Pract. 19:1-45.

De Vliegher, S., H. W. Barkema, G. Opsomer, A. de Kruif, and L. Duchateau. 2005. Association between somatic cell count in early lactation and culling of dairy heifers using Cox frailty models. J. Dairy Sci. 88:560-568.
Döpfer, D., H. W. Barkema, T. J. Lam, Y. H. Schukken, and W. Gaastra. 1999. Recurrent clinical mastitis caused by Escherichia coli in dairy cows. J. Dairy Sci. 82:80-85.

Esslemont, R. J., and M. A. Kossaibati. 1997. Culling in 50 dairy herds in England. Vet. Rec. 140:36-39.

Gröhn, Y. T., S. W. Eicker, V. Ducrocq, and J. A. Hertl. 1998. Effect of diseases on the culling of Holstein dairy cows in New York State. J. Dairy Sci. 81:966-978.

Gröhn, Y. T., R. N. González, D. J. Wilson, J. A. Hertl, G. Bennett, H. Schulte, and Y. H. Schukken. 2005. Effect of pathogen-specific clinical mastitis on herd life in two New York State dairy herds. Prev. Vet. Med. 71:105-125.

Gröhn, Y. T., D. J. Wilson, R. N. González, J. A. Hertl, H. Schulte, G. Bennett, and Y. H. Schukken. 2004. Effect of pathogen-specific clinical mastitis on milk yield in dairy cows. J. Dairy Sci. 87:3358-3374.

Hadley, G. L., C. A. Wolf, and S. B. Harsh. 2006. Dairy cattle culling patterns, explanations, and implications. J. Dairy Sci. 89:2286-2296.

Hedeker, D., O. Siddiqui, and F. B. Hu. 2000. Random-effects regression analysis of correlated grouped-time survival data. Stat. Methods Med. Res. 9:161-179.

Houben, E. H. P., A. A. Dijkhuizen, J. A. M. van Arendonk, and R. Huirne. 1993. Short- and long-term production losses and repeatability of clinical mastitis in dairy cattle. J. Dairy Sci. 76:2561-2578.

Lehtolainen, T., S. Suominen, T. Kutila, and S. Pyorala. 2003. Effect of intramammary Escherichia coli endotoxin in early- vs. latelactating dairy cows. J. Dairy Sci. 86:2327-2333.

Neerhof, H. J., P. Madsen, V. P. Ducrocq, A. R. Vollema, J. Jensen, and I. R. Korsgaard. 2000. Relationships between mastitis and functional longevity in Danish Black and White dairy cattle estimated using survival analysis. J. Dairy Sci. 83:1064-1071.

Rajala-Schultz, P. J., Y. T. Gröhn, C. E. McCulloch, and C. L. Guard. 1999. Effects of clinical mastitis on milk yield in dairy cows. J. Dairy Sci. 82:1213-1220.

SAS Institute. 2006. SAS OnlineDoc 9.1.3. SAS Institute Inc., Cary, NC.

Schukken, Y. H., Y. T. Gröhn, B. McDermott, and J. J. McDermott. 2003. Analysis of correlated discrete observations: Background, examples and solutions. Prev. Vet. Med. 59:223-240.

Seegers, H., C. Fourichon, and F. Beaudeau. 2003. Production effects related to mastitis and mastitis economics in dairy cattle herds. Vet. Res. 34:475-491.

Sviland, S., and S. Waage. 2002. Clinical bovine mastitis in Norway. Prev. Vet. Med. 54:65-78.

Thomsen, P. T., A. M. Kjelden, J. T. Sorensen, and H. Houe. 2004. Mortality (including euthanasia) among Danish dairy cows (1990-2001). Prev. Vet. Med. 62:19-33.

Vangroenweghe, F., L. Duchateau, and C. Burvenich. 2004. Moderate inflammatory reaction during experimental Escherichia coli mastitis in primiparous cows. J. Dairy Sci. 87:886-895.

Zadoks, R. N., H. G. Allore, H. W. Barkema, O. C. Sampimon, G. J. Wellenberg, Y. T. Gröhn, and Y. H. Schukken. 2001. Cow and quarter-level risk factors for Streptococcus uberis and Staphylococcus aureus mastitis. J. Dairy Sci. 84:2649-2663. 